\title{
Um olhar sobre as questões culturais no curso de Ciências da Natureza
}

\author{
Una mirada sobre las cuestiones culturales en el curso de Ciencias de la \\ Naturaleza
}

A look at cultural issues in the course of Natural Sciences

\section{Cadidja Coutinho ${ }^{1}$}

Raquel Ruppenthal ${ }^{2}$

\begin{abstract}
Resumo
O profissional da educação necessita apropriar-se da sua ciência como base para o enfrentamento dos desafios impostos à prática docente, visando a formação de uma cultura científica. Desse modo, este trabalho surge sob a perspectiva multicultural, principalmente quando o curso superior se caracteriza por multi-áreas, como é o caso da licenciatura em Ciências da Natureza (CN). Ao considerar que o Projeto Pedagógico do Curso (PPC) de um curso representa a caracterização do perfil de egresso, importantes reflexões sobre o processo formativo podem ser elucidadas através de sua análise. Para tanto, a fim de compreender como se dá a formação para a multiculturalidade no curso citado, realizou-se uma análise documental para verificar as questões referentes à educação cultural, distribuídas ao longo das componentes curriculares de Práticas Pedagógicas (PP) do PPC do curso de CN Licenciatura. A análise dos dados consistiu em verificar presença/ausência de questões culturais nos objetivos das componentes de PP. Constatou-se que das 7 componentes de PP, que contabilizam 420 horas da matriz curricular, a presença da educação cultural está assegurada em cinco delas, sendo que a PP II contempla os aspectos culturais de forma contundente. Os resultados reforçam a necessidade de discussões e de estudos sobre os princípios norteadores do multiculturalismo considerando que a enculturação científica é uma das finalidades da educação científica.
\end{abstract}

Palavras-Chave: Multiculturalismo; Práticas Pedagógicas; Ciências.

\section{Resumen}

El profesional de la educación necesita apropiarse de su ciencia como base para el enfrentamiento de los desafíos impuestos a la práctica docente, visando la formación de una cultura científica. De este modo, este trabajo surge bajo la perspectiva multicultural, principalmente cuando el curso superior se caracteriza por multi-áreas, como es el caso de la licenciatura en Ciencias de la Naturaleza (CN). Al considerar que el Proyecto Pedagógico del Curso (PPC) de un curso representa la caracterización del perfil de egresado, importantes reflexiones sobre el proceso formativo pueden ser elucidadas a través de su análisis. Para ello, a fin de comprender cómo se da la formación para la multiculturalidad en el curso citado, se realizó un análisis documental para verificar las cuestiones referentes a la educación cultural, distribuidas a lo largo de los componentes curriculares de Prácticas pedagógicas (PP) del PPC del curso de CN Licenciatura. El análisis de los datos consistió en verificar presencia / ausencia de cuestiones culturales en los objetivos de los componentes de PP. Se constató que de las 7 componentes de PP, que contabilizan 420 horas de la matriz curricular, la presencia de la educación cultural está asegurada en cinco de ellas, siendo que la PP II contempla los aspectos culturales de forma contundente. Los resultados refuerzan la necesidad de discusiones y estudios sobre los principios orientadores del multiculturalismo considerando que la enculturación científica es una de las finalidades de la educación científica.

Palabras claves: Multiculturalismo; Prácticas pedagógicas; Ciencias.

\footnotetext{
'Doutora em Educação em Ciências: Química da Vida e Saúde/ UFSM, Santa Maria; RS; Brasil; cadidjabio@gmail.com

${ }^{2}$ Doutora em Educação em Ciências: Química da Vida e Saúde/UFSM; Santa Maria; RS; Brasil; rkruppenthal@gmail.com
} 


\begin{abstract}
The education professional needs to appropriate his science as the basis for facing the challenges imposed on teaching practice, with the aim of forming a scientific culture. Thus, this work emerges from the multicultural perspective, especially when the upper course is characterized by multi-areas, such as the degree in Natural Sciences $(\mathrm{CN})$. When considering that the Course Pedagogical Project (PPC) of a course represents the characterization of the egress profile, important reflections about the formative process can be elucidated through its analysis. Therefore, in order to understand how training for multiculturalism occurs in the mentioned course, a documentary analysis was carried out to verify the questions related to cultural education, distributed throughout the curricular components of Pedagogical Practices (PP) of the PPC of the course of CN Bachelor. The data analysis consisted in verifying the presence / absence of cultural questions in the objectives of the PP components. It was verified that of the 7 components of PP, that count 420 hours of the curricular matrix, the presence of the cultural education is assured in five of them, being that the PP II contemplates the cultural aspects of forceful form. The results reinforce the need for discussions and studies on the guiding principles of multiculturalism considering that scientific enculturation is one of the aims of scientific education.
\end{abstract}

Keywords: Multiculturalism; Pedagogical practices; Sciences.

\title{
1. Questões culturais na formação de professores: considerações iniciais
}

A estreita relação entre cultura e ciência, seus aspectos subjacentes e sua importância no processo de ensino e aprendizagem tem sido motivo de recentes debates. Essas reflexões se intensificaram nas últimas décadas, devido à influência da diversidade cultural na modelagem da sociedade contemporânea e nas suas discussões (CANDAU, 2010). Silva (2011) salienta que ao mesmo tempo que a diversidade cultural das minorias se tornou mais visível, também ocorre a homogeneização ou predomínio de algumas formas culturais, promovidos pela mídia. Isso demonstra que as questões culturais estão relacionadas a questões de poder. Assim, importa que a discussão sobre as questões culturais estejam presentes nos diversos ambientes, inclusive de formação de professores.

Um ambiente de aprendizagem, em especial o espaço escolar, pode ser caracterizado como um agregado de culturas que constituem significados e exercem influências na formação social, cidadã, ética e crítica dos indivíduos. Na tentativa de definir cultura podemos destacar Lopes e Macedo (2011, p. 184) quando apontam cultura como "repertório de significados, um conjunto de sentidos socialmente criados que permitem aos sujeitos se identificarem uns com os outros". Na concepção do antropólogo Edward Taylor, é possível compreender a cultura como uma totalidade complexa de conhecimentos, crenças, artes, costumes e outras capacidades ou hábitos adquiridos pelas pessoas e transmitidos de geração em geração. A cultura é produção humana. Todos estão imersos em sua realidade cultural que influencia nas mais diversas atividades humanas, desde a convivência familiar, social e profissional, num ciclo de retroalimentação. Ou seja, a cultura está sempre em transformação. 
Do mesmo modo que o conceito de cultura, os termos "interculturalidade" e "multiculturalidade" têm sido frequentemente usados com significados diversos e numa heterogeneidade de aplicações. A concepção de interculturalidade representa uma idealização da cultura num discurso antropológico, com significados particulares a um grupo, e nesse caso, sendo essencial conceber "[...] a cultura como relação particular ao mundo de um determinado grupo, o que inclui um conjunto de normas, de valores, de modos de vida, de ritos, assim como uma língua que o grupo transmite, elementos que são constitutivos da sua identidade cultural" (CLANET, 1993, p. 108). A Ciência é uma forma cultural que é diferente da cultura social. No entanto, ela está imersa em um tempo-espaço cultural que molda a sua construção e desenvolvimento (MOURA; GUERRA, 2016), propiciando relações interculturais.

Uma relação intercultural supõe uma situação em que pessoas de culturas diferentes interagem entre si ou ainda com uma atividade que requeira tal interação (CARVALHO; MARTINS, 2014). Ainda, segundo Candau (2010):

A interculturalidade orienta processos que têm por base o reconhecimento do direito à diferença e a luta contra todas as formas de discriminação e desigualdade social. Tenta promover relações dialógicas e igualitárias entre pessoas e grupos que pertencem a universos culturais diferentes, trabalhando os conflitos inerentes a esta realidade (CANDAU, 2010, p. 99).

Neste contexto, o Ministério da Educação (MEC) publicou como uma das competências gerais previstas pela Base Nacional Comum Curricular a valorização da diversidade de saberes e de vivências culturais, incubindo a instituição escolar de conhecer e abordar as culturas plurais das famílias e das comunidades, de forma a abranger produções e formas de expressões variadas (BRASIL, 2017).

No âmbito do ensino de Ciências da Natureza, uma proposta de educação intercultural deve priorizar a coexistência de diversas culturas ou subculturas em um espaço, reconhecendo a cultura da ciência representada pelos professores e recursos didáticos, e a dos estudantes, trazidas dos seus meios sociais (COBERN, 1996; BAPTISTA, 2015). Suscita dessa forma, o debate sobre as diferenças sociais, étnicas, de gênero ou de religião que caracterizam o indivíduo que interage dentro do espaço escolar bem como as suas concepções acerca de temas ou conhecimentos científicos.

Nesta perspectiva, o conceito de cultura e o ensino de Ciências da Natureza podem estar correlacionados, uma vez que as Ciências são demarcadas pela inclusão de diferentes visões de mundo, concepções e crenças que precisam ser estudadas para que a educação 
científica se estabeleça, sem defender supremacia de nenhuma das culturas, mas que reconhecer a existência de culturas diferentes.

Para Sasseron e Carvalho (2011) esta correlação pode ser definida com a expressão enculturação científica. Esta é compreendida pelo conjunto de conhecimentos atrelados às noções, ideias e conceitos científicos, que formam a cultura científica. Os princípios idealizadores de cultura e sua extensão à educação científica constituem uma questão significativa nas pesquisas em Ciências da Natureza (GONDIM; MOL, 2008; COHEN, 2013). Isso leva a questionamentos de que maneira a formação docente, pensando no ensino de Ciências da Natureza, pode estar vinculada às questões culturais?

O cenário educacional requer debates e estudos sobre as questões culturais, que podem ser estabelecidas através de reflexões sobre os currículos de modo evitar uma abordagem superficial da diversidade cultural ou apenas o cumprimento das exigências legais. Quando se fala em currículo, é importante que se perceba as implicações de incluir ou não a diversidade cultural, cuja decisão está relacionada a uma certa ideologia ou concepção de sociedade (SILVA, 2011). É importante incluir questões culturais nos currículos não com o objetivo de naturalizar as diferenças, mas perceber que as culturas tem uma origem, uma história e que estão se transformando.

Uma proposta de formação docente multicultural deve implicar não o desenvolvimento de uma aceitação irrestrita de diferentes manifestações culturais, mas, sim, a aprendizagem das habilidades necessárias à promoção de um diálogo que favoreça uma dinâmica de crítica e autocrítica (MOREIRA, 2003, p. 87).

Assim, a reflexão sobre essa prática se torna uma exigência fundamental para os professores, a fim de contextualizar a aprendizagem de forma a ampliar suas propostas curriculares no sentido de reconhecer as necessidades sociais, políticas e econômicas dos discentes.

Nesse sentido, considerando que o ensino de Ciências da Natureza deve ponderar as expressões culturais na formação de conceitos pedagógicos, e que "a subcultura da ciência é uma integração dinâmica entre a cultura da ciência e a cultura cotidiana" (STRIEDER, 2011, p. 90), o presente trabalho visa identificar como as questões culturais estão presentes no curso de licenciatura em Ciências da Natureza, ao analisar o Projeto Pedagógico do Curso (PPC) sob a perspectiva multicultural.

\section{Percurso metodológico}


A busca, coleta e análise de dados deste trabalho é vinculada à interpretação e descrição da presença de questões culturais e assim, pode ser classificado como uma pesquisa qualititativa (FLICK, 2013) Considerando os objetivos, trata-se de pesquisa exploratória e descritiva (ANDRADE, 2009), uma vez que visa aprofundamento sobre a temática, além de descrever o fenômeno em estudo com detalhamento para compartilhar os resultados bem como promover a reflexão crítica com demais docentes.

Quando um curso superior se configura por multi-áreas, como é o caso do curso de Ciências da Natureza $(\mathrm{CN})$, a caracterização do perfil de egresso e reflexões sobre o processo formativo podem ser elucidadas através da análise do seu PPC, elegido como corpus de coleta de dados. O entendimento de que as Práticas Pedagógicas (PP) realizam a mediação entre os conhecimentos conceituais e pedagógicos a fim de ser aplicados na realidade e contexto escolar, levou a efetuar um recorte. Sendo assim, realizou-se a análise documental das componentes curriculares de PP do PPC do curso de CN Licenciatura para verificar as questões referentes à educação cultural. Justifica-se esse recorte pois o próprio documento do PPC relata a importância das componentes curriculares de PP, uma vez que possibilitam a abordagem de temas de interesse para formação em $\mathrm{CN}$, a interação com projetos e principalmente, a inserção no espaço escolar.

A Prática como Componente Curricular é inerente à formação da identidade do professor como educador, possibilitando a correlação teórico-prática e o movimento entre saber, saber fazer, saber compreender/refletir sobre o que faz na busca de significados na gestão e resolução de situações próprias do ambiente da educação escolar. Deve também promover a articulação das diferentes práticas numa perspectiva interdisciplinar (UNIPAMPA, 2011, p. 33).

Para coleta dos dados, fez-se inicialmente uma leitura flutuante das ementas das componentes curriculares de PP, em seguida, os objetivos destas foram analisadas com a finalidade de verificar a presença/ausência de questões culturais. Os resultados foram organizados através de informações numéricas e apontamentos descritivos das ocorrências, assim como, uma análise e interpretação qualitativa das informações, e bem como das suas contribuições para formação inicial em CN.

\subsection{Resultados e discussão}

A incorporação do termo "cultura" no texto do PPC de um curso superior não garante que este abarque toda a amplitude que a temática exige. Porém, ao pensar em um curso de formação docente, os aspectos culturais ganham empatia uma vez que o egresso ao se deparar com seu campo de trabalho necessita de embasamento teórico e prático para exercer a sua profissão de forma satisfatória e ética. 
Pensando nisso, a organização curricular de um curso de licenciatura precisa abarcar as questões culturais, estimulando o diálogo entre os conceitos científicos e a diversidade cultural. Sendo assim, o curso de CN Licenciatura propõe uma formação interdisciplinar nas áreas de química, física e biologia, como possibilidade de melhoria da qualidade do ensino das áreas supracitadas. Ainda, prevê a integração dos componentes das áreas que versam os conhecimentos científicos ao eixo educação que considera os aspectos pedagógicos que fundamentam a atuação do licenciando em $\mathrm{CN}$, o que demonstra um caráter intercultural ao curso.

O objetivo geral do curso é "formar professores de Ciências da Natureza aptos a exercerem a docência no Ensino Fundamental e Médio, dentro de uma perspectiva interdisciplinar levando-os à pesquisa e a reflexão ética perante a sociedade e a natureza" (UNIPAMPA, 2018), que implicitamente demonstra a preocupação com as questões culturais. O curso está organizado em dez semestres, compostos por atividades complementares, componentes curriculares obrigatórios e complementares. Entre as disciplinas obrigatórias estão as PP, alvo de análise no presente trabalho. No total são sete PP, distribuídas ao longo do curso, nos I, III, IV, V, VI, VII e VIII semestres.

Considerando que o curso de CN Licenciatura apresenta correlações com os aspectos culturais, realizou-se uma análise documental que consistiu em verificar presença/ausência de questões culturais nas ementas e nos objetivos das componentes de PP. Constatou-se que nas 7 componentes de PP, que totalizam 420 horas da matriz curricular, a presença das questões culturais está assegurada, às vezes de maneira mais implícita, como no caso das PP III, IV, V e VII, ora de maneira contundente e explícita, como nas PP I, II e VI. O Quadro 1 apresenta o nome das componentes curriculares e a ementa das mesmas. Os grifos representam expressões/palavras que caracterizam a perspectiva cultural atrelada a disciplina. Considerando que a cultura agrupa o conjunto de práticas, linguagem, costumes que são compartilhados por um grupo, percebe-se que cada PP dá destaque a uma forma cultural distinta.

Quadro 1 - Relação de Práticas Pedagógicas, ementário e aspecto cultural em destaque.

\begin{tabular}{|l|l|l|}
\hline $\begin{array}{l}\text { COMPONENTE } \\
\text { CURRICULAR }\end{array}$ & EMENTA & $\begin{array}{l}\text { ASPECTO CULTURAL } \\
\text { EM DESTAQUE }\end{array}$ \\
\hline
\end{tabular}


RELACult - Revista Latino-Americana de Estudos em Cultura e Sociedade

Revista Latinoamericana de Estudios en Cultura y Sociedad | Latin American Journal of Studies in Culture and Society

V. 05, ed. especial, abr., 2019, artigo n ${ }^{\circ} 1167$ | claec.org/relacult |e-ISSN: 2525-7870

\begin{tabular}{|c|c|c|}
\hline $\begin{array}{l}\text { Práticas Pedagógicas I: } \\
\text { Introdução às Ciências da } \\
\text { Natureza }\end{array}$ & $\begin{array}{l}\text { Conceito de Ciências da Natureza. Importância de } \\
\text { atividades práticas em Ciências da Natureza. Funcionamento, } \\
\text { função e uso de laboratórios. Segurança, técnicas e operações } \\
\text { básicas empregadas em laboratórios: uso de EPI e EPC. Uso } \\
\text { de vidrarias e preparo de soluções. Sistema internacional de } \\
\text { unidades. Pesquisa em Ciências da Natureza. }\end{array}$ & Cultura científica \\
\hline $\begin{array}{l}\text { Práticas Pedagógicas II: } \\
\text { diversidade, antropologia, } \\
\text { ética e inclusão }\end{array}$ & $\begin{array}{l}\text { Cultura, culturas regionais, processo educativo frente } \\
\text { aos diferentes grupos culturais e a construção da identidade. } \\
\text { Conceitos fundamentais - Ética; Diversidade; Inclusão. } \\
\text { Legislação educacional brasileira específica sobre os conceitos } \\
\text { fundamentais na escola. Diretrizes Curriculares nacionais } \\
\text { vigentes para os conceitos fundamentais. Multiculturalismo e } \\
\text { construção da cidadania. As temáticas transversais } \\
\text { (sexualidade, gênero, corporeidade, relações étnico-raciais, } \\
\text { cidadania, educação ambiental, inclusão, acessibilidade, entre } \\
\text { outros) no Ensino de Ciências da Natureza e práticas escolares. } \\
\text { Reflexão crítica sobre as temáticas. Produção textual reflexiva. } \\
\text { Seminário socializador. }\end{array}$ & $\begin{array}{l}\text { Diversidade cultural- } \\
\text { social }\end{array}$ \\
\hline $\begin{array}{l}\text { Prática Pedagógica III: } \\
\text { Educação Ambiental }\end{array}$ & $\begin{array}{c}\text { Princípios, objetivos e conceitos básicos da } \\
\text { Educação Ambiental (EA). História da EA Mundial e } \\
\text { Brasileira. Documentos Legais Brasileiros para EA. Órgãos } \\
\text { Ambientais Brasileiros e suas atribuições. EA como uma } \\
\text { ciência Transdisciplinar e como um tema transversal na } \\
\text { Escola. Formação de Educadores Ambientais. Atividades e } \\
\text { materiais didáticos em Educação Ambiental. Temáticas } \\
\text { Ambientais aplicadas ao contexto escolar. Educação para } \\
\text { Sustentabilidade e Conservação do Meio Ambiente. Educação } \\
\text { Ambiental ética e o contexto socioambiental. Cultura e } \\
\text { Patrimônio Ambiental. }\end{array}$ & $\begin{array}{c}\text { Diversidade } \\
\text { socioambiental }\end{array}$ \\
\hline $\begin{array}{l}\text { Práticas Pedagógicas IV: } \\
\text { Planejamento }\end{array}$ & $\begin{array}{l}\text { Concepções de planejamento educacional. O } \\
\text { planejamento educacional no Brasil. O planejamento } \\
\text { participativo na escola - projeto político pedagógico. O } \\
\text { processo de planejamento e desenvolvimento de ensino. Tipos } \\
\text { de plano: plano de ensino, plano de aula, projeto. } \\
\text { Desenvolvimento de planos interdisciplinares. }\end{array}$ & Cultura educacional \\
\hline $\begin{array}{l}\text { Prática Pedagógica } \quad \text { V: } \\
\text { Avaliação Educacional }\end{array}$ & $\begin{array}{l}\text { Pressupostos epistemológicos e vertentes teóricas da } \\
\text { avaliação educacional. Avaliação como política numa } \\
\text { perspectiva histórica e conceitual. Níveis, tipos e modalidades } \\
\text { de avaliação de sistemas, organizações, programas e projetos } \\
\text { educacionais. Aspectos metodológicos de avaliação } \\
\text { educacional. Avaliação e a construção do conhecimento. } \\
\text { Avaliação e o processo educativo. Desenvolvimento de } \\
\text { Instrumentos avaliativos. Pesquisa sobre avaliação escolar. }\end{array}$ & Cultural educacional \\
\hline
\end{tabular}


RELACult - Revista Latino-Americana de Estudos em Cultura e Sociedade

\begin{tabular}{|c|c|c|}
\hline $\begin{array}{l}\quad \text { Prática } \\
\text { Pedagógica VI: Educação e } \\
\text { Mídias }\end{array}$ & $\begin{array}{l}\text { Políticas Públicas e as Tecnologias de Informação e } \\
\text { Comunicação (TIC); relação entre TIC e Educação; aplicação } \\
\text { das TIC e exemplos em processos de ensino e aprendizagem } \\
\text { em Ciências da Natureza; reflexão sobre o papel do professor e } \\
\text { do estudante na sociedade da informação. Uso de ferramentas } \\
\text { de comunicação, softwares educacionais e ferramentas de } \\
\text { busca para o ensino e pesquisa em Ciências. Ferramentas de } \\
\text { comunicação. Potencialidades e limitaçães do uso das TIC no } \\
\text { Ensino de Ciências da Natureza. Avaliação crítica de softwares } \\
\text { e outras mídias utilizadas em ambientes de aprendizagem em } \\
\text { Ciências. }\end{array}$ & Cultura digital \\
\hline $\begin{array}{l}\text { Prática Pedagógica VII: } \\
\text { Metodologia no ensino de } \\
\text { Ciências da Natureza }\end{array}$ & $\begin{array}{l}\text { Metodologia de aprendizagem ativa. Os três } \\
\text { momentos pedagógicos. Oficinas temáticas. Unidades de } \\
\text { aprendizagem. Ciência em contexto. Aprendizagem baseada } \\
\text { em problemas. Ensino e aprendizagem baseados em projetos. } \\
\text { Atividades experimentação. Atividades lúdicas. Abordagem } \\
\text { temática. Problematização e Contextualização. }\end{array}$ & Cultura educacional \\
\hline
\end{tabular}

Fonte: Autores (2018)

A análise das ementas permite afirmar que cada um dos componentes apresenta um viés cultural diferente. Ao compreendermos que a cultura refere-se às práticas sociais que tem um significado para um grupo, podemos inferir que as PP estão permeadas pelas perspectivas científica, educacional, socioambiental, digital e cultural-social, dando um caráter intercultural ao conjunto. Nesse sentido, por tratar-se de um curso de licenciatura, vale destacar a presença da cultura educacional. Sabe-se que nas escolas e outros espaços formais de educação, há uma cultura e saberes que são típicos desse círculo.

Quando se fala em cultura educacional, infere-se que nas escolas e outras instituições de ensino apresentam formas típicas de compreender e de interação com situações ou fenômenos, e que não fazem parte de outras culturas. Por exemplo, nas escolas é visível a preocupação com o planejamento a curto, médio e longo prazos, bem como a avaliação desse processo. Dessa forma, a presença de três PP voltadas a vivência e reflexão sobre essa cultura, é possível afirmar que há a preocupação do curso em formar o licenciando a partir das questões culturais próprias das escolas. Em relação a alocação das PP no decorrer do curso, é possível dizer que as PP voltadas a cultura educacional podem se apropriar das discussões e reflexões realizadas nas demais PP, o que favorece uma formação intercultural.

Conforme Moura; Guerra (2016) as Ciências são integrantes da cultura em nosso tempo e espaço, e dessa forma é importante entender que as Ciências fazem parte da dinâmica social e cultural a fim de construir questões e respostas em nosso mundo. Dessa forma, a presença da cultura científica na PP I se justifica particularmente por se tratar de um curso multi-áreas, nas quais os aspectos das Ciências da Natureza são primordiais. Busca-se formar 
indivíduos capazes de reconhecer a Ciência como um processo em expansão, e dar aplicabilidade aos conceitos científicos em relação aos conhecimentos prévios dos discentes, ou seja, conciliar a educação científica com as expressões culturais individuais construídas pelo aluno em espaço/tempo diferentes do ambiente educacional.

Também é importante salientar que a presença da cultura digital é relevante no atual contexto social e mostra a possibilidade de aproximação da mesma com o ambiente escolar, integrando-a às atividades de ensino e aprendizagem. As tecnologias já fazem parte do cotidiano dos jovens, e existe, portanto, a necessidade de desenvolver alunos que possam trabalhar com as tecnologias, conectadas de forma social e cultural. Além disso, são um elemento essencial do conhecimento e da sociedade da informação. De fato, essas permitem que os conhecimentos sejam processados, transformados e tornem-se rapidamente um elemento estratégico inovador para a promoção da educação na maioria dos países (ORTEGA NAVAS, 2017). Ou seja, podem favorecer a difusão de diferentes aspectos culturais, rompendo barreiras geográficas.

A diversidade socioambiental também se faz presente nas ementas das PP do curso, o que sinaliza a necessidade de reconhecer a educação ambiental como intercessora do processo de aprendizagem da temática ecológica, além de repercutirem a importância de uma dimensão crítica para o ensino desta. Os atributos da educação ambiental relacionam-se à complexidade do saber ambiental, estreitando relações entre os conceitos e a realidade (LEFF, 2012), ou seja, a apresentação da terminologia associada aos aspectos da ecologia, da ecologia humana e da sustentabilidade, bem como, os aspectos culturais associados à exploração ou manutenção dos recursos naturais.

Quanto à diversidade cultural-social nota-se que as PP reconhecem a existência de diferentes culturas num mesmo espaço, ou seja, a multiculturalidade. Um território diversificado que forma a sociedade, composta por culturas que ocupam posições não igualitárias em função das relações de poder estabelecidas (LIMA, 2014). Da mesma forma, é fundamental a reflexão sobre as diferentes culturas na formação inicial, principalmente num curso de licenciatura, mostrando que não há a necessidade de aceitação irrestrita de todas as manifestações culturais, mas sim a emergência pelo desenvolvimento de competências necessárias ao estabelecimento de diálogo, da crítica e autocrítica (MOREIRA, 2003).

Convém ressaltar que a PP II: diversidade, antropologia, ética e inclusão" contempla aspectos culturais num sentido mais amplo. Quando a ementa destaca a preocupação em desenvolver o diálogo acerca das culturas regionais, dos processos educativos frente aos diferentes grupos culturais, bem como das diversidades étnicas, de gênero visando a 
construção da cidadania, percebe-se a importância que esta componente dá às questões culturais na formação dos licenciandos. Destaca-se que esta componente está alocada no 3 semestre, o que possibilita que a mesma tenha alguma influência sobre as demais componentes curriculares, sejam PP ou não, fomentando a reflexão acerca de como o professor precisa considerar aspectos culturais no seu fazer docente.

Da mesma forma, evidencia-se que em um curso superior, em especial de licenciatura, existe a oportunidade de aproximar os conceitos teóricos científicos com as vivências culturais. A elaboração do PPC está diretamente atrelada ao perfil de egresso e principalmente a um currículo formador que se pretende seguir. Este por sua vez, precisa considerar de forma ampla os aspectos sociais, tecnológicos, científicos e culturais.

[...] currículo é algo que se desenvolve na dinâmica da escola e até mesmo de outras instituições; ele é gestado no ventre da cultura dos sujeitos que dele se servirão para fins educacionais. Onde se postula ensinar algo, há que se desenvolver um currículo e este está diretamente ligado à cultura, uma vez que é ela quem vai "dar o tom" de como esse currículo vai se desenhar. Seja na escola ou fora dela, pois outros grupos sociais que também ensinam desenvolvem seus currículos, ainda que de forma menos organizada e menos formatada em moldes convencionais (SILVEIRA; SOUSA, 2018).

O Quadro 2 apresenta a relação de objetivos de cada PP. Os objetivos referem-se a metas de aprendizagem a ser alcançadas por intermédio das estratégias de aula e/ou habilidades que se espera que sejam desenvolvidas ao longo da componente. Dessa forma, é importante que os objetivos sejam examinados a fim de perceber o alcance das perspectivas culturais de cada PP. 
Quadro 2 - Relação entre os objetivos de cada PP.

\begin{tabular}{|c|c|}
\hline COMPONENTE CURRICULAR & OBJETIVOS \\
\hline $\begin{array}{l}\text { Práticas Pedagógicas I: Introdução } \\
\text { às Ciências da Natureza }\end{array}$ & $\begin{array}{l}\text { Compreender o conceito de Ciências da Natureza e a sua importância para a } \\
\text { sociedade; } \\
\text { Discutir o ensino de Ciências da Natureza na Educação Básica; } \\
\text { Propor estratégias para o ensino de Ciências da Natureza por meio de atividades } \\
\text { práticas; } \\
\text { Dinamizar as inter-relações entre: teoria, prática e reflexão crítica sistemática; } \\
\text { Compreender conceitos de segurança, técnicas e operações básicas empregados } \\
\text { em laboratórios de Ciências da Natureza. } \\
\text { Contribuir para construção dos saberes docentes, bem como para o contato } \\
\text { desses com a realidade social. }\end{array}$ \\
\hline $\begin{array}{l}\text { Práticas Pedagógicas II: diversidade, } \\
\text { antropologia, ética e inclusão }\end{array}$ & $\begin{array}{l}\text { Compreender e investigar as relações entre a sociedade incluindo condições de } \\
\text { vida, indivíduo, meio ambiente, educação e escola na contemporaneidade. } \\
\text { Compreender as relaçães entre as Ciências da Natureza e a construção de } \\
\text { identidades pessoais, sociais e culturais. } \\
\text { Conhecer a literatura e legislação educacionais relacionadas aos temas } \\
\text { transversais (sexualidade, gênero, corporeidade, relações étnico-raciais, } \\
\text { cidadania, educação ambiental, inclusão, acessibilidade, entre outros) no Ensino } \\
\text { de Ciências da Natureza e práticas escolares. } \\
\text { Divulgar e produzir conhecimentos, bem como atitudes, posturas e valores que } \\
\text { eduquem cidadãos quanto à pluralidade étnico-racial, tornando-os capazes de } \\
\text { interagir e de negociar objetivos comuns que garantam, a todos, respeito aos } \\
\text { direitos legais e valorização de identidade, na busca da consolidação da inclusão } \\
\text { na sociedade brasileira. }\end{array}$ \\
\hline $\begin{array}{l}\text { Prática Pedagógica III: Educação } \\
\text { Ambiental }\end{array}$ & $\begin{array}{l}\text { Compreender a história e a importância da Educação Ambiental para a } \\
\text { construção de sociedades sustentáveis. } \\
\text { Desenvolver a capacidade de compreensão da temática ambiental de forma } \\
\text { holística e no âmbito transdisciplinar. } \\
\text { Aprender a utilizar de maneira coerente a Educação Ambiental na Escola. }\end{array}$ \\
\hline
\end{tabular}


RELACult - Revista Latino-Americana de Estudos em Cultura e Sociedade

\begin{tabular}{|c|c|}
\hline $\begin{array}{l}\text { Práticas Pedagógicas IV: } \\
\text { Planejamento }\end{array}$ & $\begin{array}{l}\text { Compreender o conceito de planejamento, destacando os seus elementos } \\
\text { básicos, as finalidades, os níveis, as etapas e partes integrantes do planejamento } \\
\text { educacional; visando a reflexão sobre o planejamento no contexto da educação } \\
\text { brasileira. } \\
\text { Estabelecer relações entre o planejamento da escola e o currículo escolar; } \\
\text { Compreender como o planejamento e a organização escolar envolvem filosofia, } \\
\text { políticas públicas e conhecimento do contexto nacional e regional; } \\
\text { Elaborar diferentes planejamentos. }\end{array}$ \\
\hline $\begin{array}{c}\text { Prática Pedagógica V: Avaliação } \\
\text { Educacional }\end{array}$ & $\begin{array}{l}\text { Compreender as concepçães de avaliação e o uso dos instrumentos e processos } \\
\text { avaliativos como eixo condutor do trabalho pedagógico no contexto da escola, } \\
\text { bem como os objetivos e função dos sistemas de avaliação da educação } \\
\text { brasileira. } \\
\text { Compreender as principais concepções avaliativas; } \\
\text { Compreender o significado e o processo de avaliação no contexto do sistema e } \\
\text { da escola; } \\
\text { Analisar a trajetória da avaliação e a evolução de seu conceito; } \\
\text { Caracterizar as funções, critérios e categorias da Avaliação Educacional; } \\
\text { Analisar a função da Avaliação no Planejamento e sua operacionalização; } \\
\text { Analisar o papel da avaliação na atual legislação brasileira; } \\
\text { Desenvolver instrumentos avaliativos. }\end{array}$ \\
\hline $\begin{array}{c}\text { Prática Pedagógica VI: Educação e } \\
\text { Mídias }\end{array}$ & $\begin{array}{l}\text { Compreender como as Tecnologias da Informação e Comunicação (TIC) podem } \\
\text { auxiliar o processo ensino e aprendizagem (presencial ou distância) e discutir as } \\
\text { implicações do uso de suas ferramentas na Educação, em especial no Ensino de } \\
\text { Ciências da Natureza. } \\
\text { Analisar diferentes softwares usados no Ensino de Ciências da Natureza e o } \\
\text { papel de cada um no processo de ensino e aprendizagem; } \\
\text { Verificar a possibilidade de integração das diferentes tecnologias usadas na } \\
\text { Educação; } \\
\begin{array}{l}\text { Avaliar os impactos promovidos pelas TIC em diferentes contextos } \\
\text { educacionais. }\end{array}\end{array}$ \\
\hline $\begin{array}{c}\text { Prática Pedagógica VII: } \\
\text { Metodologia no ensino de Ciências } \\
\text { da Natureza }\end{array}$ & $\begin{array}{l}\text { Introduzir aos acadêmicos metodologias de Ensino de Ciências que lhes } \\
\text { permitam um olhar crítico e reflexivo sobre a prática docente. } \\
\text { Promover a formação dos acadêmicos em propostas e metodologias do Ensino } \\
\text { de Ciências da Natureza. } \\
\text { Oportunizar reflexões e vivências acerca da complexidade de situações } \\
\text { pedagógicas que podem ocorrer nas escolas e nas práticas vinculadas ao } \\
\text { cotidiano escolar do Ensino de Ciências da Natureza. }\end{array}$ \\
\hline
\end{tabular}

Fonte: Autores (2018) 
Observando os objetivos contidos nas PP é possível identificar trechos que salientam a questão cultural como alvo para a formação inicial docente. Na PP I destaca-se a preocupação com as questões sociais e as contribuições do ensino de Ciências para a realidade social, ou seja, para uma sociedade que em geral se forma a partir de diferentes concepções e aproxima saberes e valores. Também é visível a preocupação com a inserção do licenciando com a cultura científica e com a prática da Ciência. Já na PP II todos os objetivos se direcionam para reflexões acerca da diversidade cultural, salientado as questões de cultura regional, gênero, as minorias num enfoque crítico e reflexivo.

Os objetivos da PP III retratam a preocupação com as questões de meio, com um enfoque na observação ambiental de forma holística, considerando a intercultura. A PP IV preocupa-se com as questões políticas atreladas ao processo educacional, que precisam considerar os contextos nacionais, regionais e locais na sua elaboração.

Nos objetivos das PP V e VI não se observa diretamente as questões interculturais. Por fim, na PP VII fala-se em vivências, o que pode aproximar os conteúdos acadêmicos ao cotidiano do aluno, e dessa forma, propiciar a percepção das relações existentes entre os contextos de atuação com as diversas culturas.

Perante o exposto, reforça-se a necessidade de discussões e de estudos sobre os princípios norteadores do multiculturalismo considerando que a enculturação científica é uma das finalidades da educação científica. Quando o curso de licenciatura preconiza a formação de profissionais capacitados ao exercício da docência deve considerar além dos conteúdos específicos das áreas, mas também, as habilidades necessárias à prática docente. Entre elas destaca-se o espírito crítico, as atitudes e especialmente o respeito à diversidade de saberes, de valores e de culturas.

\section{E agora? Considerações e perspectivas}

Pela análise realizada neste trabalho, foi possível observar a preocupação do curso em oportunizar a reflexão e discussão acerca das questões culturais na formação de professores, numa perspectiva intercultural. Importa salientar que a análise considerou apenas as componentes curriculares agrupadas como PP, que representam parte obrigatória da grade curricular. No entanto, o recorte realizado justifica-se em função de que essas componentes apresentar-se ao longo do curso como mediadoras entre as questões de conhecimento científico e os saberes pedagógicos, além de viabilizarem a inserção do acadêmico no ambiente escolar. 
Por outro lado, essa escolha leva a considerar se haveria diferença nos resultados se todas as componentes curriculares tivessem sido analisadas. O caráter intercultural observado nas PP se manteria? Ou o foco cairia na cultura científica? Isso leva a perceber a necessidade de novos estudos considerando toda a grade curricular do curso, a fim de verificar como as questões culturais estão inseridas nas demais disciplinas. Da mesma forma, é necessário apontar que o resultado obtido refere-se a uma graduação, em uma localidade específica e, que talvez, se a análise for realizada em outros contextos, os resultados podem diferir dos que aqui foram encontrados.

No entanto, em função das questões tão em voga na atualidade, refletir acerca da presença das questões culturais nas grades curriculares dos cursos de formação de professores, bem como em outros cursos se faz cada vez mais necessário e pertinente. Além disso, também importa observar como se dão as práticas envolvendo a cultura nos espaços formais e nãoformais de educação, o que pode trazer novos campos de pesquisa no futuro.

\section{Referências}

ANDRADE, M. M. Introdução a metodologia do trabalho científico: elaboração de trabalhos na graduação. 9. ed. São Paulo: Atlas, 2009. 176p.

BAPTISTA, G. C. S. Do cientificismo ao diálogo intercultural na formação do professor e ensino de ciências. Interacções, v. 10, n. 31, 2015.

BRASIL. Ministério da Educação. Base Nacional Comum Curricular. Resolução CNE/CP N 2, de 22 de dezembro de 2017. 2017.

CANDAU, V. M. F. Multiculturalismo e educação: desafios para a prática pedagógica. In: V. M. Candau; A. F. Moreira (Org.). Multiculturalismo: diferenças culturais e práticas pedagógicas. Petrópolis: Vozes, p. 13-37. 2010.

CARVALHO, F. O.; MARTINS, M. C. A interculturalidade na formação do pedagogo brasileiro: território de arte \& cultura. Educação Online, n. 15, 2014, 157p.

CLANET, C. L'interculturel. Introduction aux approches interculturelles en education et en sciences humaines. Toulouse: Presses Universitaires du Mirail, 1993. 397p.

COBERN, W. W. Constructivism and non-Western science education research. International Journal of Science Education, v.4, n.3, 1996, 302p.

COHEN, M. C. R. Autoria e compartilhamentos de saberes: contribuições para a formação de professores de ciências/biologia. Atas do IX Encontro Nacional de Pesquisa em Educação em Ciências - IX ENPEC Águas de Lindóia, SP. 2013.

FLICK, U. Introdução à Metodologia de Pesquisa. Porto Alegre: Penso, 2013. 216p. 
GONDIM, M. S. C.; MOL, G. S. Saberes populares e ensino de ciências: possibilidades para um trabalho interdisciplinar. Química Nova na Escola, n. 30, p. 03-09. 2008.

LIMA, E. F. A construção de práticas pedagógicas inter/multiculturais no ensino fundamental e os saberes docentes. Revista Diálogo Educacional. Curitiba, v. 14, n. 42, p. 395-414. 2014.

LOPES, A. C.; MACEDO, E. Teorias de Currículo. São Paulo: Cortez, 2011. 156p.

MOREIRA, A. F. B. Currículo, diferença cultura e diálogo. In: Educação e Sociedade, Campinas: CEDES, v. 23, n. 79, p. 15-38. 2003.

MOURA, C. B.; GUERRA, A. História Cultural da Ciência: Um Caminho Possível para a Discussão sobre as Práticas Científicas no Ensino de Ciências? Revista Brasileira de Pesquisa em Educação em Ciências, v. 16, n. 3, p. 725-748, 2016.

ORTEGA-NAVAS, M. C. The use of new technologies as a tool for the promotion of health education. Procedia - Social and Behavioral Sciences, n. 237, p. 23 - 29, 2017.

SASSERON, L. H.; CARVALHO, A. M. P. Alfabetização Científica: uma revisão bibliográfica. Investigações em Ensino de Ciências, v. 16(1), p. 59-77. 2011.

SILVA, T. T. Documentos de identidade: uma introdução às teorias do currículo. Belo Horizonte: Autêntica, 2011. 156 p.

SILVEIRA, M. C. O.; SOUSA, F. Concepções de professores sobre currículo e cultura. In: III Simpósio Internacional sobre Desenvolvimento Profissional Docente/III Congresso Internacional sobre Formação e Desenvolvimento Profissional Docente. Even3, 2018.

STRIEDER, D. M. O ensino de ciências no contexto teuto-brasileiro: cultura local e cultura científica. Cascavel: Coluna do Saber. 2011.

UNIPAMPA. Diretrizes Orientadoras para Elaboração dos Projetos Pedagógicos das Licenciaturas da Universidade Federal do Pampa. 2011. Disponível em: http://porteiras.r.unipampa.edu.br/portais/prograd/files/2012/01/Dcto-Diretrizes-PPC-

Licenciatura.pdf . Acesso em: 11 jan. 2019.

UNIPAMPA. Projeto Pedagógico de Curso. Curso Ciências da Natureza - Licenciatura. 2018. Disponível em: http://dspace.unipampa.edu.br/bitstream/riu/110/7/PPC_Ci\%C3\%AAncias\%20da\%20Naturez a_Dom\%20Pedrito.pdf. Acesso em: 11 jan. 2019. 